\title{
Sistema de Calibração de EMissões EM TemPo Real
}

\author{
André Gouvêa ${ }^{1}$, Marcello Depieri ${ }^{1}$, Fernando Urcino ${ }^{1}$, Gledson Rocha ${ }^{1}$, Alexandre Maria ${ }^{1}$, \\ Alexsandro da Silva ${ }^{1}$ e Alberto Bucci ${ }^{1}$ \\ ${ }^{1}$ Magneti Marelli Sistemas Automotivos Indústria e Comércio Ltda.
}

E-mails: andre.gouvea@magnetimarelli.com; marcello.depieri@magnetimarelli.com; fernando.urcino@magnetimarelli.com; gledson.rocha@magnetimarelli.com; alexandre.maria@magnetimarelli.com; alexsandro.silva@magnetimarelli.com; alberto.bucci@magnetimarelli.com

\section{RESUMO}

O presente trabalho aborda o desenvolvimento de uma ferramenta inovadora para o trabalho de calibração veicular de emissões, que utilizando as informações provenientes do veículo associadas aos valores das concentrações dos gases de escapamento pré e pós catalisador, lidos em tempo real, reduzem significativamente o tempo de calibração, garantindo maior agilidade e qualidade nos resultados obtidos.

Em um Laboratório de emissões veiculares contendo bancadas Bag e Modal, com dinamômetro de chassis, foram implementadas saídas analógicas nos sistemas de análises pré e pós catalisador para fornecer em tempo real as concentrações dos gases medidos nas bancadas de análise modal.

Estes canais fornecem as concentrações medidas de cada gás em valores de tensão (0-10V), que são tratadas e novamente convertidas em concentração através de cálculos matemáticos disponíveis nos laptops dos engenheiros calibradores, aproveitando de todos os recursos de sensibilidade e precisão (dual range) disponíveis nas bancadas dos analisadores.

Com estes dados, torna-se possível gerar calibrações de emissões com alta precisão, grande qualidade e rapidez, uma vez que as respostas dos gases de escapamento podem ser associadas aos parâmetros disponíveis da central eletrônica do motor, possibilitando ao engenheiro condições de calibração otimizada de dirigibilidade, controle de sonda, diagnose OBD2 etc.

\section{INTRODUÇÃO}

Utilizado há mais de cem anos na maioria dos projetos de veículos, o conceito de motores a combustão interna Ciclo Otto assim como seus respectivos sistemas de injeção tiveram diversos marcos importantes de desenvolvimento tecnológicos, devido a fatores tais como maximização do desempenho, redução de consumo, conforto, dirigibilidade e principalmente a necessidade do controle de emissões de poluentes resultantes da queima dos combustíveis [1]. 
Entre estes marcos estão a criação e o desenvolvimento do sistema de controle de mistura ar/combustível, realimentados por uma sonda de oxigênio, sensores de temperatura, detonação, etc., enfim desenvolvimentos que possibilitaram gradativamente uma maior eficiência térmica e energética da combustão, além do conforto para os usuários. Estes sistemas passaram de mono combustíveis a bicombustíveis, tri-combustíveis, flexfuel, híbridos, etc. [2].

As atividades de calibração de emissões são iniciadas em bancadas dinamométricas de motor e ajustados nos dinamômetro de chassi, utilizando o veículo em sua configuração definitiva ou uma que seja representativa, com as quais são considerados os parâmetros dinâmicos, de coast down e os padrões de homologação do país em que o veículo será comercializado.

No Brasil por exemplo, o ciclo utilizado para homologação é ciclo ABNT-NBR 6601(FTP 75), que consiste em um teste com três fases distintas (partida a frio, transiente e partida a quente), totalizando 17,86 km em $1874 \mathrm{~s}$ (acrescido o período de pausa) conforme Figura 01 [2][3].

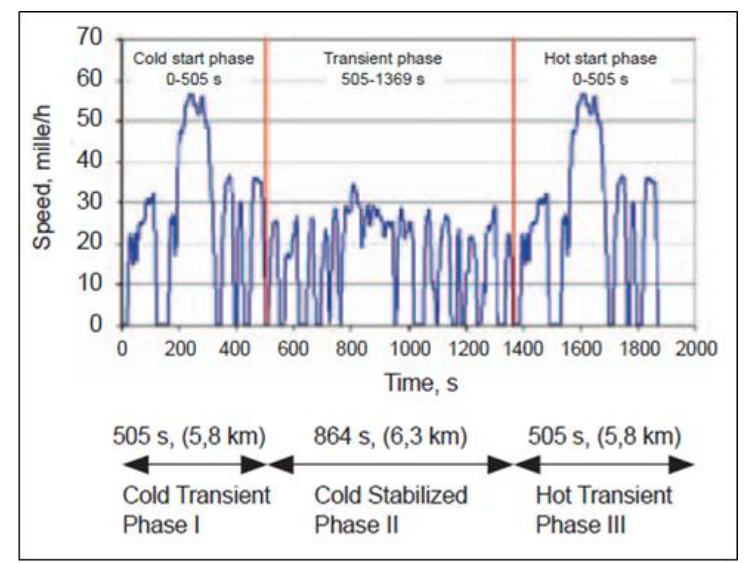

Figura 01 - Ciclo Urbano ABNT-NBR 6601

\section{SISTEMA DE CALIBRAÇÃO DE EMISSÕES EM TEMPO REAL}

O resultado de emissões é normalmente obtido após a conclusão do ensaio, depois de encerradas as leituras dos balões de amostragem têm-se os resultados de emissões dos poluentes e consumo; a análise modal também é processada após a determinação da razão de diluição, podendo gerar relatório de eficiência de massa ou concentração de cada gás.

Para uma eficiente calibração, os engenheiros precisam analisar o resultado do ciclo de homologação ponto a ponto, calculando a eficiência catalítica, verificando spikes de emissões gasosas e controlando o funcionamento da sonda de oxigênio; porém, como estes dados não estão disponíveis durante o ensaio, as correções na calibração, quando necessárias, ocorrem de forma demorada e muitas vezes empírica, obrigando o engenheiro a repetir os ensaios muitas vezes até atingir os objetivos desejados.

Para solucionar estas dificuldades, foi desenvolvido um sistema inovador de análise em tempo real através da implementação de saídas analógicas, instaladas diretamente na bancada de análise modal de concentração de gases, dedicadas aos valores de concentrações gasosas pré e pós catalisador, que são aquisitadas pelo engenheiro calibrador através de equipamentos $A / D$ 
Converter juntamente com todos os parâmetros funcionais do motor, conforme Figura 02 e Figura 03.

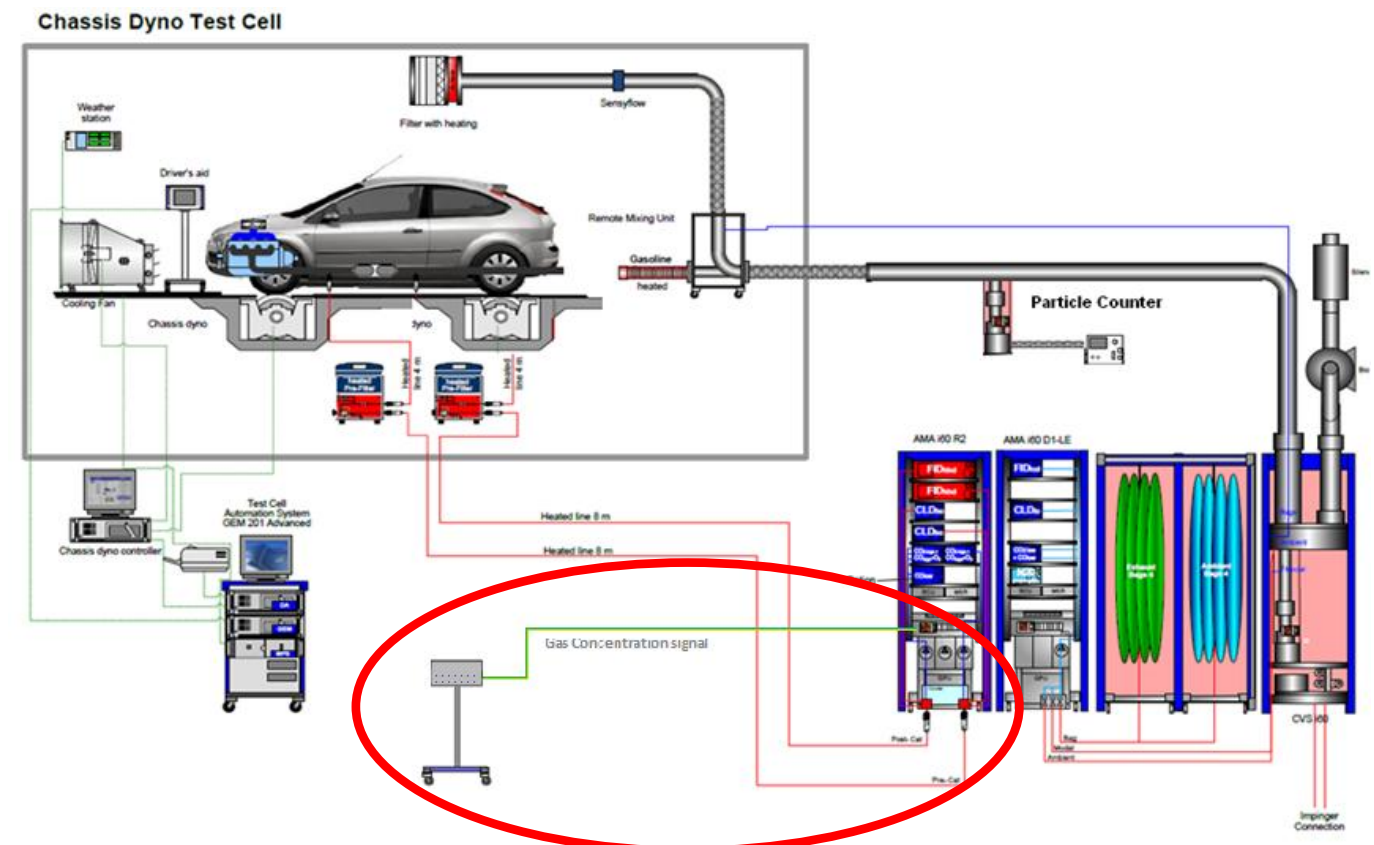

Figura 02 - Banco de Emissões veiculares com dinamômetro de chassis e sistema de aquisição inovador.

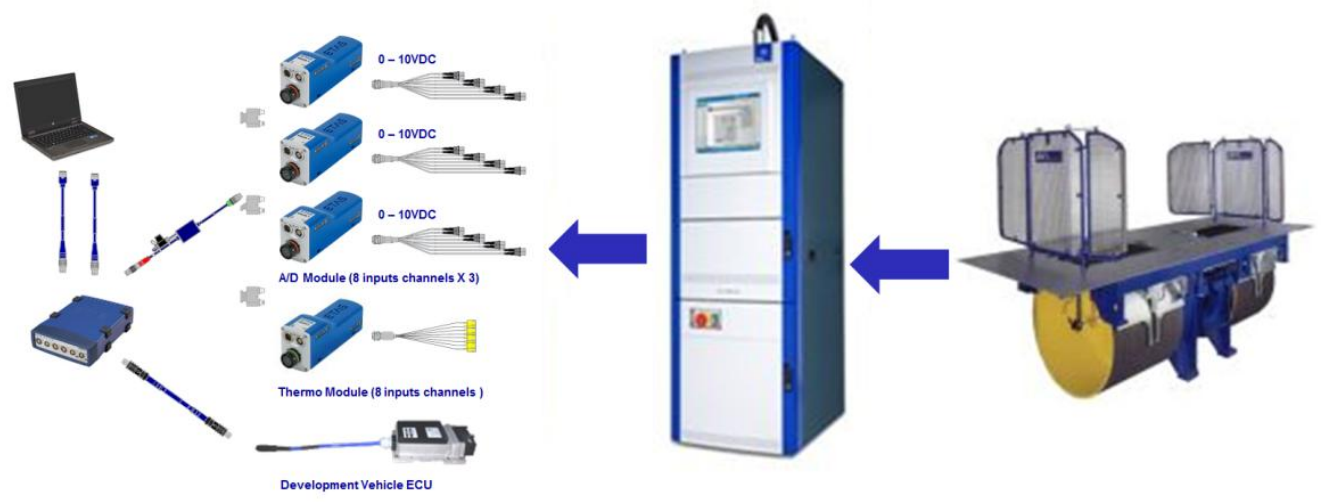

Figura 03 - Instrumentação do sistema.

Os sinais elétricos das concentrações gasosas pré e pós catalisador disponíveis para análise são:

- Hidrocarbonetos Totais(THC)

- Metanos $\left(\mathrm{CH}_{4}\right)$

- Óxidos Nitrosos $\left(\mathrm{NO}_{\mathrm{X}}\right)$

- Monóxidos de Carbono (CO)

- Dióxidos de Carbono $\left(\mathrm{CO}_{2}\right)$

- Oxigênio $\left(\mathrm{O}_{2}\right)$

- Força $(\mathrm{N})$

- Velocidade $(\mathrm{km} / \mathrm{h})$ 
Com exceção aos canais de força e velocidade, cada um dos demais sinais possui duas faixas de leitura de alta sensibilidade, sendo uma para altas concentrações, utilizadas principalmente no início do teste com veículo ainda frio, e outra faixa para baixas concentrações utilizadas principalmente durante as fases quentes dos ciclos. O chaveamento das faixas ocorre toda vez que o valor lido estiver em $90 \%$ do fundo de escala da primeira faixa (de menor concentração) conforme mostrado na figura 04.

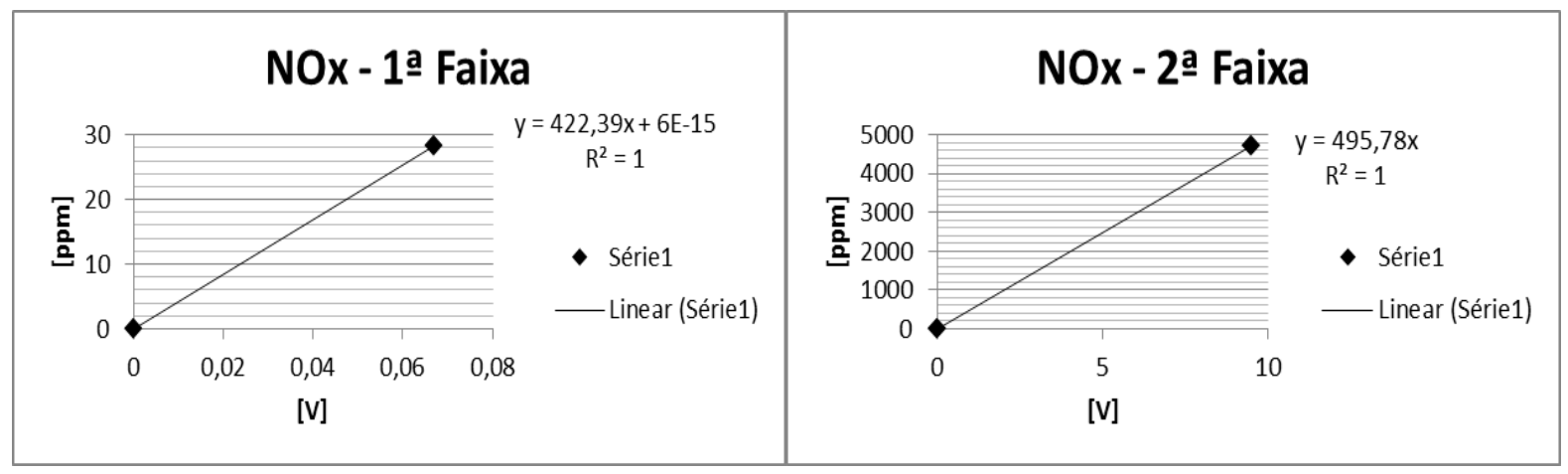

Figura 04 - Duplo Range para leitura NOx pré catalisador

Como a análise de cada gás tem um delay que pode ser quantificado, foi desenvolvido um sistema de buffer calculado para sincronizar todas as respostas, de forma que a aquisição tenha o mesmo referencial de tempo para todos os pontos conforme figura 05 .

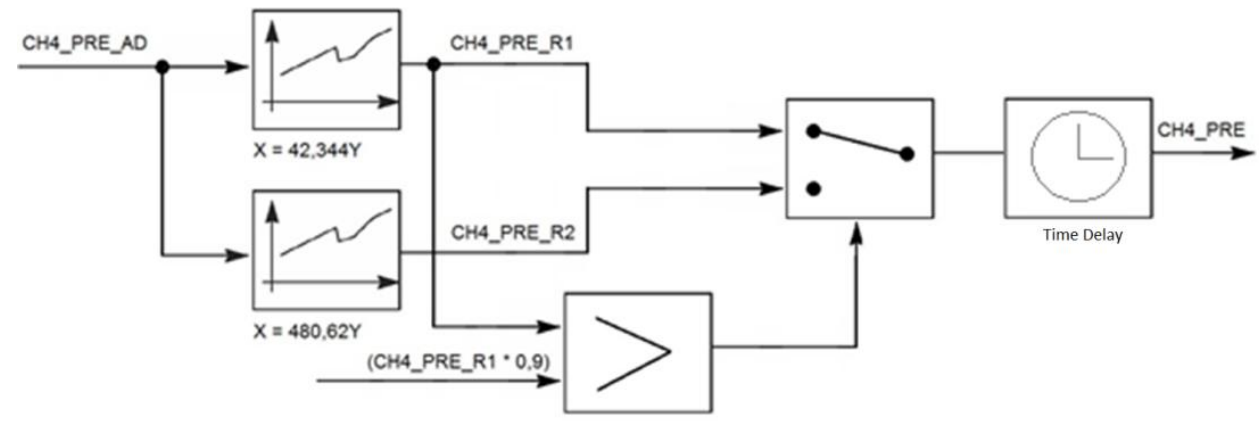

Figura 05 - Exemplo de Duplo Range, chaveamento e Time Delay dos gases.

\section{BENEFÍCIOS NOVA METODOLOGIA}

Entre as calibrações que trariam os maiores benefícios desta nova metodologia e que influenciam os resultados finais de emissões, pode-se destacar:

- Gerenciamento das sondas de oxigênio:

O gerenciamento das sondas é o maior responsável pelo controle das emissões veiculares em regimes estabilizados. O sistema age através de um controlador proporcional-integral, que recebe um feedback do sinal elétrico advindo da sonda lambda. A resposta da atuação dos 
injetores sobre o conversor catalítico é imediata. Desta forma um sistema que monitora em tempo real a resposta dos gases, permite ao engenheiro aplicador um tempo de calibração significativamente inferior juntamente a uma maior precisão, conforme apresentado nas Figuras 06 e 07.

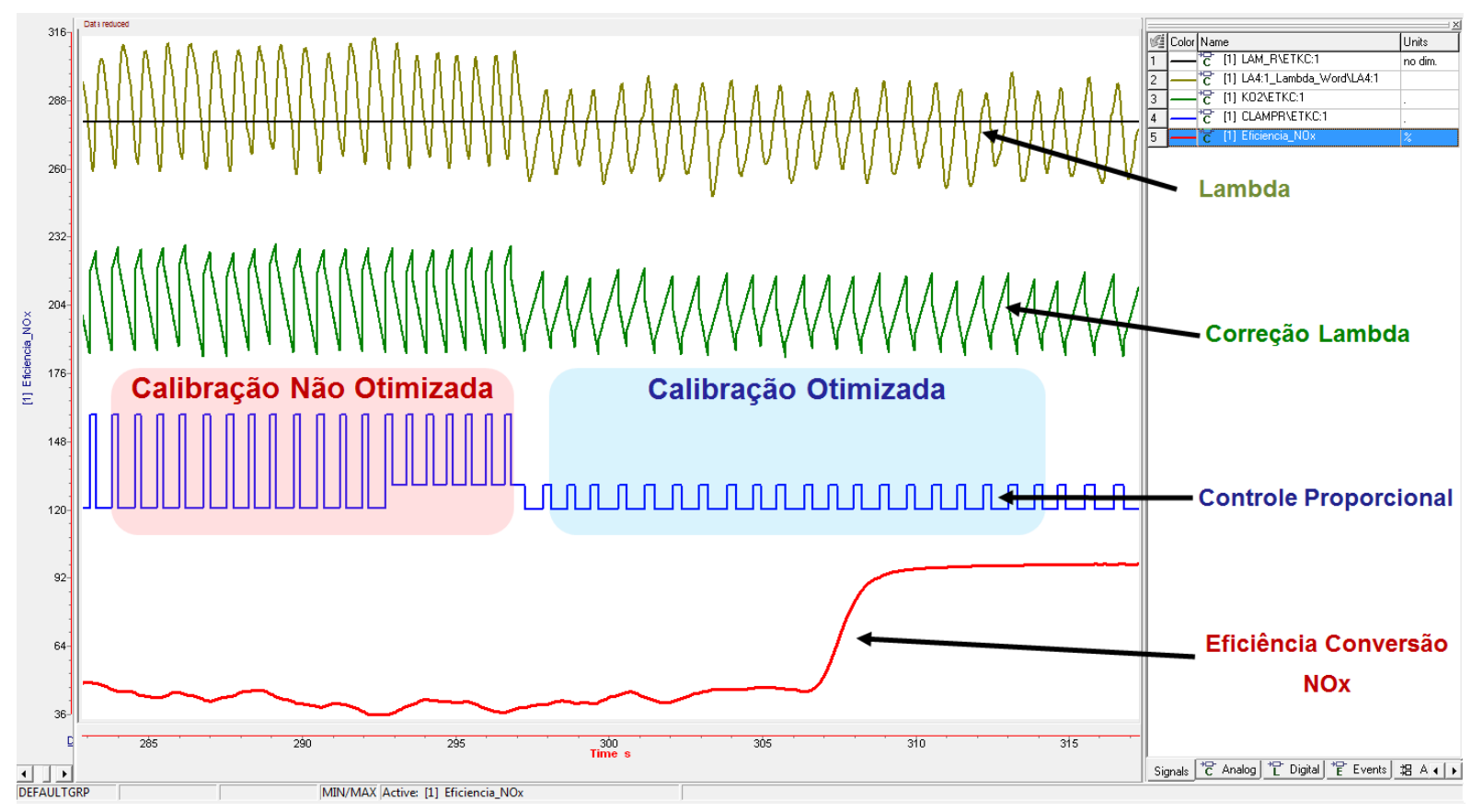

Figura 06 - Melhora maior que 60\% da eficiência de conversão do NOx.

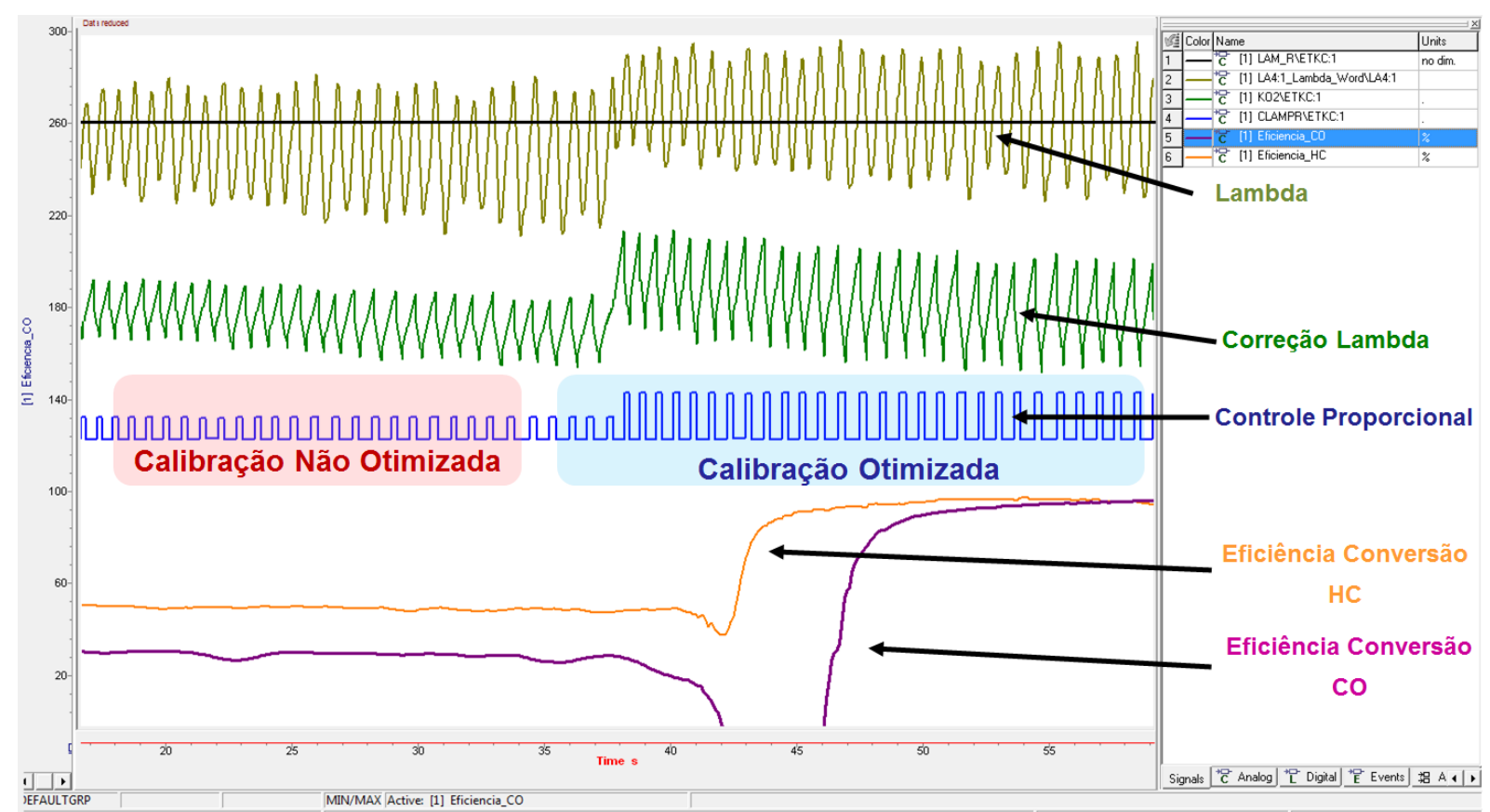

Figura 07 - Controle Sonda, melhora maior que $60 \%$ da eficiência de conversão do CO e $40 \%$ da eficiência de conversão do HC. 
- Calibração dos transitórios em emissões:

Com o sistema apresentado, é possível ler em tempo real, em cada ponto do ciclo ABNTNBR 6601, os picos de emissões dos gases, dando condições de fazer as modificações de calibração relativas e avaliar rapidamente a resposta dos gases relacionando-as com as devidas manobras, conforme Figura 08.

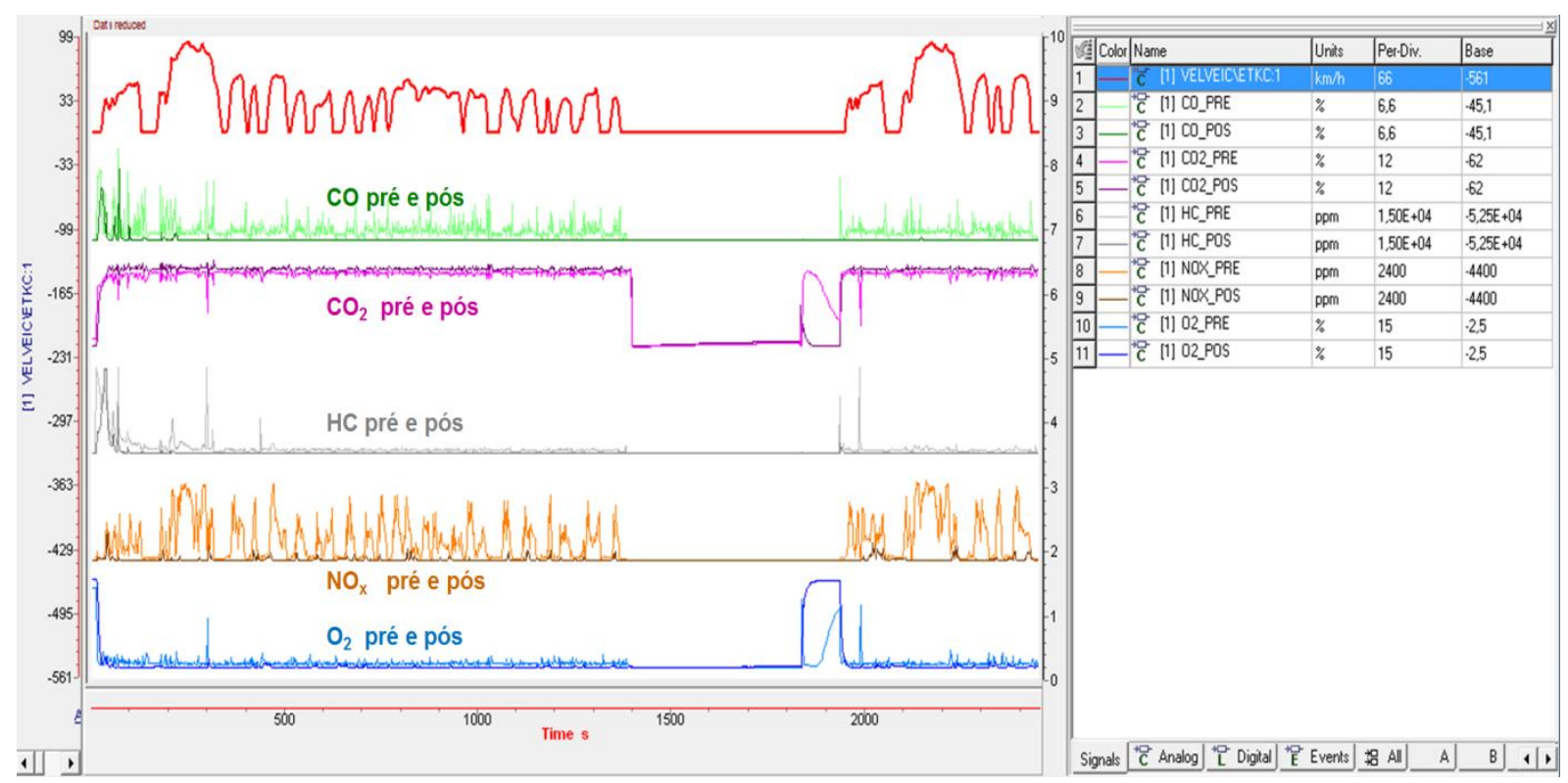

Figura 08 - Ciclo de homologação com valores de emissões pré e pós aquisitados em tempo real juntamente com os parâmetros de injeção.

- Purga do oxigênio armazenado após desacelerações:

Toda vez que uma desaceleração do veiculo gera um CUTOFF do motor (corte de combustível), uma grande quantidade de oxigênio fica armazenada dentro do catalisador, dificultando a conversão catalítica na retomada ou na próxima aceleração. Com este novo método é possível controlar e calibrar em tempo real uma dosagem controlada de mistura rica para purgar o oxigênio armazenado, possibilitando novamente a correta capacidade de conversão do catalisador.

- Calibração de diagnose do catalisador:

Algumas funções para diagnosticar a eficiência do catalisador são realizadas através de um gerenciamento intrusivo da sonda de oxigênio, resultando em alguns casos em picos de emissão. Com o sistema de aquisição em tempo real, é possível determinar com extrema rapidez o melhor momento onde realizar esta diagnose, de forma a não resultar em um valor acumulado fora dos limites de emissões. 


\section{CONCLUSÃO}

Esta nova metodologia associada aos resultados obtidos com as bancadas de emissões de ultima geração, fornece aos engenheiros um auxilio importante para realizar calibrações de emissões em real time e com extrema precisão nos resultados.

Utilizando as rápidas respostas dos analisadores de gases em real time durante os ensaios de emissões ou em qualquer outra situação de dirigibilidade, seja em condições estabilizadas ou em transientes, é possível gerar calibrações mais eficientes, com maior qualidade.

Associando os valores de concentração de gases poluentes com os parâmetros lidos diretamente do veículo, é possível a elaboração de relatórios mais coesos e confiáveis.

\section{AGRADECIMENTOS}

A Magneti Marelli, a equipe de Calibração Veicular e a equipe do Laboratório Emissões Veiculares.

\section{REFERÊNCIAS}

[1] MINISTÉRIO DO MEIO AMBIENTE, Resolução CONAMA n415, 2009.

[2] MINISTÉRIO DO MEIO AMBIENTE, Resolução CONAMA No 299, 2001.

[3] ASSOCIAÇÃO BRASILEIRA DE NORMAS TÉCNICAS, NBR 6601, Veículos rodoviários automotores leves, 2012. 